\title{
Estudios auxiliares en el diagnóstico diferencial de tumores epiteliales renales con células granulares
}

\author{
Arias $\mathrm{LF}^{1,4}$, Hernández $\mathrm{S}^{1,2}$, Bocardo $\mathrm{G}^{3}$, González L $\mathrm{L}^{1}$, Vélez $\mathrm{M}^{4}$, Arteta $\mathrm{A}^{4}$, Blanco $\mathrm{J}^{1}$. \\ Departamentos de ${ }^{1}$ Patología y ${ }^{3}$ Urología, Hospital Clínico San Carlos, Madrid, España; ${ }^{2}$ Centro Nacional de \\ Investigaciones Oncológicas (CNIO), Madrid, España. ${ }^{4}$ Grupo PRYT, Departamento de Patología, Facultad de \\ Medicina, Universidad de Antioquia, Medellin, Colombia.
}

Actas Urol Esp 2008;32(2):194-201

\section{RESUMEN}

\section{ESTUDIOS AUXILIARES EN EL DIAGNÓSTICO DIFERENCIAL DE TUMORES EPITELIALES RENALES} CON CÉLULAS GRANULARES

Introducción y objetivos: El diagnóstico diferencial de neoplasias renales con células granulares puede tener dificultades e implicaciones en la ontogenia y el pronóstico. Nuestro propósito es caracterizar el patrón de inmunotinción y buscar un mejor panel de inmunohistoquímica (IHQ) útil en su diagnóstico diferencial.

Métodos: Estudiamos con hierro coloidal (método de Mowry modificado) y 22 inmunomarcadores de uso común 22 carcinomas convencionales (CC), 37 carcinomas cromófobos (CPC), 8 oncocitomas (OC) y 7 carcinomas de conductos colectores (CDC) con células granulares. Los casos sin diagnóstico completamente claro fueron excluidos.

Resultados: La tinción con hierro coloidal fue citoplasmática, difusa, fuerte y reticular en 32 de los 37 CPC. El patrón difuso y fuerte no fue observado en ninguno de los otros tumores. El panel diagnóstico más útil fue citoqueratina 7 (CK7)/CD10/vimentina (vim). Todos los OC fueron negativos para los 3 anticuerpos. El perfil más común para CC fue CK7-/CD10+/vim+ y el perfil para CPC fue CK7+/CD10-/vim-. Los CDC no mostraron un perfil particular. Con estos tres marcadores encontramos una especificidad mayor del 90\% para el diagnóstico diferencial. Si adicionamos el hierro coloidal la especificidad fue del $100 \%$.

Conclusiones: Los rasgos morfológicos, la tinción con hierro coloidal con el método de Mowry modificado y la inmunomarcación con CK7/CD10/vim permite el diagnóstico final con alta especificidad. Sin embargo, actualmente no existe un marcador o panel $100 \%$ sensible y especifico.

Palabras clave: Células granulares. Carcinoma renal. Inmunohistoquímica. Hierro coloidal. Oncocitoma.

\begin{abstract}
ANCILLARY STUDIES IN THE DIFFERENTIAL DIAGNOSIS OF EPITHELIAL RENAL CELL TUMORS WITH GRANULAR CELLS Introduction and objectives: Differential diagnosis of renal neoplasms with granular cells may pose difficulties and implications on ontogeny and prognosis. Our aims are to characterize the pattern of immunostaining and to search for a useful diagnosis panel.

Methods: We studied with colloidal iron staining (Mowry`s modified method) and 22 commonly used immunomarkers 22 conventional carcinomas (CC), 37 chromophobe carcinomas (CPC), 8 oncocytomas (OC), and 7 collecting duct carcinomas (CDC) with granular cells. Cases with not entirely clear diagnosis were excluded.

Results: Colloidal iron staining was diffuse, strong, reticular, and cytoplasmic in $32 \mathrm{CPC}$ cases, the diffuse and strong pattern was not observed in other tumors. The more useful diagnostic panel was cytokeratin 7 (CK7)/CD10/vimentine (vim). The 8 OC were negative for the three antibodies. The most common profile for CC was CK7-/CD10+/vim+, the CPC profile was $\mathrm{CK} 7+/ \mathrm{CD} 10$-/vim-, and CDC did not show a particular profile. With these three antibodies specificity was $>90 \%$ for the differential diagnosis. Adding colloidal iron staining specificity was $100 \%$.

Conclusions: Morphologic features, colloidal iron staining (modified Mowry's method), and immunostaining with CK7/CD10/vim permit the final diagnosis with high specificity. However, a 100\% specific marker does not exist at the present time.
\end{abstract}

Keywords: Granular cells. Renal cell carcinoma. Immunohistochemistry. Colloidal iron. Oncocytoma.

Abreviaturas: CC: carcinoma renal convencional; CDC: carcinoma de conductos colectores; CPC: carcinoma cromófobo; OC: oncocitoma; CK: citoqueratina; vim: vimentina; IHQ: inmunohistoquímica; TMA: "tissue microarray" (matriz de tejidos). 
$\mathrm{E}^{1}$ espectro morfológico del carcinoma renal incluye varios tipos en los que es prominente la presencia de células con citoplasma granular. El conjunto de tumores de células renales con apariencia granular incluye oncocitoma (OC), carcinoma cromófobo de células renales (variante granular o eosinofilica) (CPC), carcinoma convencional (variante granular) (CC), carcinoma papilar renal (tipo II o variante eosinofilica) y algunos carcinomas de conductos colectores (CDC). Si bien muchos de estos tumores pueden ser fácilmente diagnosticados basados sólo en su morfologia, hay neoplasias con características citoarquitecturales similares en las que el diagnóstico diferencial puede no ser fácil. Es posible que las implicaciones terapéuticas de un diagnóstico equivocado no sean siempre un problema vital, pero, es muy importante clasificar correctamente todas las lesiones tumorales para conocer su histogénesis, su pronóstico y las implicaciones terapéuticas futuras. Aunque la clasificación de las neoplasias epiteliales renales refleja las características genéticas distintivas de las categorías de tumores, ésta se basa primordialmente en criterios histomorfológicos ${ }^{1,2}$. Un panel de inmunohistoquímica (IHQ) que contenga anticuerpos positivos y negativos para cada uno de los tipos de tumor que muestran células granulares podría mejorar la precisión del diagnóstico.

Las tinciones con hierro coloidal, citoqueratina (CK) 7, CD10, CD20 y otros inmunomarcadores han sido consideradas útiles en el diagnóstico dife- rencial $^{3-10}$, pero no se conoce aún un panel o un marcador especifico para confirmar cada tipo preciso de tumor renal entre los que están constituidos por células granulares.

Estudiamos 74 tumores renales con células granulares: $22 \mathrm{CC}, 37 \mathrm{CPC}, 8 \mathrm{OC}$ y $7 \mathrm{CDC}$, con 22 marcadores de IHQ comunmente empleados. Nuestros objetivos son caracterizar el patrón de inmunotinción con estos anticuerpos y buscar un mejor panel útil en el diagnóstico del tipo específico de tumor.

\section{MATERIAL Y MÉTODOS}

En una revisión de 474 tumores renales epiteliales resecados en el Hospital Clínico San Carlos, Madrid, entre 1984 y 2004, encontramos 88 tumores de células renales compuestos total o principalmente por células granulares. De éstos, 4 fueron excluidos debido a que el tejido fue inadecuado para el estudio. En otros 10 casos el subtipo histológico del tumor epitelial no fue completamente claro y no fueron incluidos en el presente trabajo. Todas las muestras disponibles fueron revisadas por dos patólogos (LFA y JB) y categorizadas de acuerdo a la más reciente clasificación de la Organización Mundial de la Salud ${ }^{1}$. Los criterios de inclusión de cada tipo histológico aparecen en la Tabla $1^{2,11}$ (Fig. 1). En todos los casos evaluamos todos los cortes del tumor. El tejido elegido para la realización de la histoquímica y la IHQ fue rigurosamente obtenido de áreas con presencia de células granulares.

Tabla 1. Características histológicas principales en el diagnóstico diferencial de tumores renales con células granulares; criterios usados para inclusión en cada categoría ${ }^{2,11}$

\begin{tabular}{|c|c|c|c|c|}
\hline & C. convencional & C. cromófobo & Oncocitoma & C. conductos colectores \\
\hline Arquitectura & $\begin{array}{l}\text { Vasos finos } \\
\text { abundantes } \\
\text { interconectados }\end{array}$ & $\begin{array}{l}\text { Células grandes } \\
\text { cerca septos } \\
\text { vasculares y } \\
\text { pequeñas en centro } \\
\text { de nidos tumorales }\end{array}$ & $\begin{array}{l}\text { Disposición en } \\
\text { láminas y nidos. } \\
\text { A veces área } \\
\text { central cicatricial. } \\
\text { Zonas laxas acelulares }\end{array}$ & $\begin{array}{l}\text { Tubular, papilar, } \\
\text { infiltrativo, desmoplasia, } \\
\text { displasia en conductos } \\
\text { adyacentes }\end{array}$ \\
\hline Citologia & $\begin{array}{l}\text { Membrana } \\
\text { citoplasmática } \\
\text { delgada. } \\
\text { Algunas áreas } \\
\text { con células claras }\end{array}$ & $\begin{array}{l}\text { Citoplasma } \\
\text { reticular pálido. } \\
\text { Acentuación } \\
\text { membrana celular: } \\
\text { aspecto célula } \\
\text { vegetal. Variante } \\
\text { eosinofilica }\end{array}$ & $\begin{array}{l}\text { Células finamente } \\
\text { granulares en } \\
\text { láminas y nidos, } \\
\text { ocasionalmente } \\
\text { túbulos. Nunca } \\
\text { papilas }\end{array}$ & $\begin{array}{l}\text { Células pleomórficas, } \\
\text { núcleos de alto grado }\end{array}$ \\
\hline Halos perinucleares & Ausentes & Presentes & Ausentes & Ausentes \\
\hline Células claras & Presentes & $\begin{array}{l}\text { Presentes, diferentes } \\
\text { a las del C .convencional }\end{array}$ & $\begin{array}{l}\text { Ocasionales, aisladas, } \\
\text { no en grupos }\end{array}$ & Ausentes \\
\hline
\end{tabular}




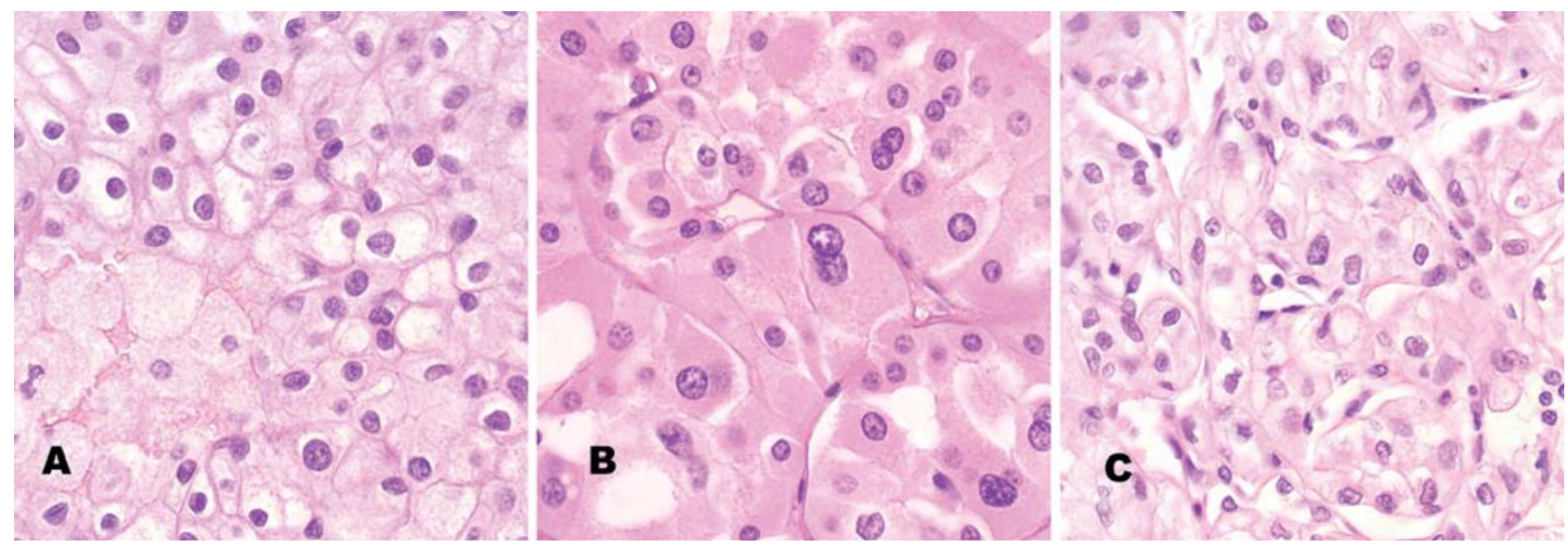

FIGURA 1. Comparación entre las características histológicas típicas del carcinoma cromófobo, el oncocitoma y el carcinoma convencional. (A) Células eosinofílicas con frecuentes halos perinucleares; hay abundante citoplasma reticular pálido, con acentuación periférica de la granularidad hacia la membrana celular: carcinoma cromófobo. (B) Células con abundante citoplasma finamente granular y eosinofílico, distribuidas en nidos y túbulos, sin halos perinucleares: oncocitoma. (C) Arquitectura alveolar, compacta, sólida con característica vascularización prominente que se interconecta; no hay acentuación en las membranas celulares: carcinoma convencional. A, B y C: Hematoxilina-eosina, aumento original $\mathrm{X} 400$.

Los bloques de tejido incluidos en parafina, correspondientes a los fragmentos seleccionados en cada uno de los 74 casos, fueron utilizados para construir una matriz de tejido ("tissue microarray" TMA) como se describió previamente ${ }^{12,13}$. Los cortes teñidos con hematoxilinaeosina (H\&E) fueron empleados como guía para seleccionar áreas del tumor de la cual tomamos dos cilindros por caso, de un milímetro de diámetro cada uno, para construir el nuevo bloque con los 148 cilindros de los 74 tumores. Incluimos además, como controles, 8 casos (16 cilindros) de tejido renal cortical y medular normales (riñones donantes descartados para trasplante o áreas no tumorales de riñones resecados por tumor). Los cilindros fueron ordenados con exactitud en el nuevo bloque de parafina receptor, de $40 \mathrm{~mm} \times 23 \mathrm{~mm}$, utilizando un espacio de $0,5 \mathrm{~mm}$ entre cada cilindro, con un aparato manual para preparación de matrices de tejidos ("manual tissue arrayer") (Beecher Instruments, Silver Spring, Maryland, USA). De este bloque obtuvimos cortes de $4 \mu \mathrm{m}$ de espesor, en un micrótomo convencional, para las tinciones de histoquímica e IHQ. El número de cada caso y la posición de referencia de cada cilindro fueron tabulados por ordenador para su identificación exacta. De los archivos de historias clínicas obtuvimos datos de edad y sexo, presentación clínica, hallazgos ecográficos y estadio de la
UICC. El seguimiento clínico fue también determinado por la revisión de historias clínicas y fue retrospectivo.

Los cortes de TMA fueron teñidos con $\mathrm{H} \& \mathrm{E}$ y hierro coloidal, en este último manteniendo el pH de 1,9 o menos para la solución de trabajo, como fue descrito por Lillie y Fullmer ${ }^{14}$ y por Tickoo et $\mathrm{al}^{9}$ (método modificado de Mowry). En resumen, los cortes desparafinados e hidratados fueron tratados con solución de acido acético al $12 \%$ durante 3 minutos, teñidos en solución de hierro coloidal durante 60 minutos, lavados con agua destilada hasta la decoloración de los cortes, teñidos con el método Perl, lavados dos veces con agua destilada, contrastados con solución de van Gieson por 5 minutos, pasados por alcohol absoluto y xilol, y finalmente montados. La solución de hierro coloidal fue preparada el mismo día de su utilización mezclando una solución comercial de hierro coloidal con ácido acético glacial en una relación de 4 a 1 y ajustando, si fuese necesario, el pH a 1,9 o menos; nosotros obtuvimos los mejores resultados con un $\mathrm{pH}$ de 1,5 ó 1,6. La tinción fue interpretada como positiva si fue citoplasmática, difusa, fuerte y reticular.

\section{Inmunohistoquimica}

Para la IHQ, los cortes de $4 \mu \mathrm{m}$ fueron desparafinados en xilol durante 30 minutos y rehidratados 
usando concentraciones progresivas de etanol. Los anticuerpos utilizados, proveedores, diluciones y recuperación antigénica utilizada aparecen en la Tabla 2. La IHQ fue realizada utilizando el sistema Envision ${ }^{\circledR}$ con peroxidasa (Dako, Glostrup, Dinamarca) y diaminobenzidina como el cromógeno revelador de la positividad. La IHQ fue realizada con el sistema automatizado de tinción Biotek-1000 (Biotek Solutions Inc, Tucson, AZ, USA). En los casos con positividad conocida en tejido renal normal, los cilindros de tejido renal incluidos en el TMA sirvieron como controles positivos. En casos sin positividad conocida en el tejido renal normal usamos controles positivos de otros tejidos en cristales diferentes.
Los resultados fueron considerados como positivos cuando la superficie celular (CD10), el citoplasma y el núcleo (S-100) o el citoplasma y/o la membrana celular (todos los demás anticuerpos) se tiñeron en más del 5\% de las células tumorales. El nivel de tinción fue clasificado como 1+ (tinción $>5 \%$ y $£ 30 \%$ de las células tumorales), 2+ (tinción $>30 \%$ y $£ 50 \%$ ) y $3+$ (tinción $>50 \%$ ). La tinción de Ki67 fue determinada como porcentaje aproximado de células con tinción nuclear, este porcentaje indica el indice proliferativo del tumor.

\section{Análisis Estadístico}

Como estimadores de tendencia central empleamos la media y la mediana de los resultados, y

Tabla 2. Anticuerpos utilizados en la inmunohistoquímica

\begin{tabular}{|c|c|c|c|c|}
\hline Anticuerpo & Clon & Dilución & Fuente & Pretratamiento \\
\hline EMA & E-29 & $1: 300$ & DAKO, Glostrup, Dinamarca & Vaporizador en buffer citrato \\
\hline CEA & II7 & $1: 1000$ & DAKO, Glostrup, Dinamarca & Vaporizador \\
\hline Vimentina & Vim3B4 & $1: 500$ & Novocastra, Newcastle, UK & Vaporizador \\
\hline S-100 & policlonal & $1: 1000$ & DAKO, Glostrup, Dinamarca & Vaporizador \\
\hline Ulex & policlonal & $1: 100$ & DAKO, Glostrup, Dinamarca & Vaporizador \\
\hline Desmina & DE-R-11 & $1: 200$ & DAKO, Glostrup, Dinamarca & Vaporizador \\
\hline Actina & HHF35 & $1: 50$ & DAKO, Glostrup, Dinamarca & Vaporizador \\
\hline CD 10 & $56 \mathrm{CG}$ & $1: 20$ & Novocastra, Newcastle, UK & Vaporizador - EDTA \\
\hline CD 15 & C3D-1 & $1: 25$ & DAKO, Glostrup, Dinamarca & Vaporizador \\
\hline CD 34 & QBEnd10 & $1: 100$ & DAKO, Glostrup, Dinamarca & Vaporizador \\
\hline НМВ 45 & НMB 45 & $1: 50$ & DAKO, Glostrup, Dinamarca & Vaporizador \\
\hline CK 7 & OV-TL12/30 & $1: 100$ & DAKO, Glostrup, Dinamarca & Vaporizador - EDTA \\
\hline CK 8 & TS1 & $1: 40$ & Novocastra, Newcastle, UK & Vaporizador \\
\hline CK 10 & LHP1 & predilución & Novocastra, Newcastle, UK. & Tripsina \\
\hline CK 18 & DC-10 & $1: 40$ & Novocastra, Newcastle, UK. & Vaporizador \\
\hline CK 19 & b-170 & $1: 150$ & Novocastra, Newcastle, UK. & Tripsina \\
\hline CK 20 & KS20.8 & $1: 50$ & Novocastra, Newcastle, UK. & Vaporizador \\
\hline HWCK & $34, \mathrm{E} 12$ & $1: 25$ & DAKO, Glostrup, Dinamarca & Vaporizador \\
\hline CD 99 & $12 \mathrm{E} 7$ & $1: 50$ & DAKO, Glostrup, Dinamarca & Vaporizador \\
\hline Cromogranina & DAK-A3 & $1: 200$ & DAKO, Glostrup, Dinamarca & Vaporizador \\
\hline Sinaptofisina & SY38 & $1: 50$ & DAKO, Glostrup, Dinamarca & Vaporizador \\
\hline Ki67 & KiS5 & $1: 10$ & DAKO, Glostrup, Dinamarca & Vaporizador - EDTA \\
\hline
\end{tabular}

CK: citoqueratina; EDTA: ácido etilendiaminotetraacético; HWCK: citoqueratina de alto peso molecular. 
como estimadores de dispersión la desviación típica (DT) y valores mínimo y máximo. Empleamos la prueba exacta de Fisher para la comparación de proporciones. Para determinar sensibilidad, especificidad, valor predictivo positivo (VPP) $\mathrm{y}$ valor predictivo negativo (VPN) consideramos verdaderos positivos los casos de cada tipo tumoral que mostraban su perfil característico de acuerdo con los resultados (con CK7, CD10 y vimentina, ver en resultados). Como verdaderos negativos para cada tipo histológico los casos que no eran de ese tipo y no presentaban su perfil de IHQ. Falsos negativos los tumores con resultado diferente al característico de su tipo histológico. Y falsos positivos para un tipo histológico los casos que mostraban su perfil de IHQ siendo de otro tipo histológico. La prueba de Kruskal-Wallis fue utilizada para comparar el indice proliferativo entre los cuatro tipos de tumor, ya que se requiere análisis de la varianza de muestras independientes sin una distribución normal (no paramétricas). Las diferencias fueron consideradas estadisticamente significativas cuando $P$ fue $<0,05$ en distribución de dos colas. Los cálculos (excepto el análisis de rendimiento diagnóstico) fueron realizados con el software SPSS ${ }^{\circledR}$, versión 11,5 (SPSS, Chicago, IL).

\section{RESULTADOS}

\section{Características clinicas}

La edad media de los pacientes fue 62,9 años $\pm 11,9$ (mediana 64; mínimo - máximo: 32-84); de los cuales $35(47,3 \%)$ fueron hombres. Disponemos de adecuada información clínica y de seguimiento en 56 pacientes $(75,7 \%)$. En 17 pacientes $(30,9 \%)$ se describen sintomas asociados con el tumor: hematuria, dolor, masa palpable y pérdida de peso. En los otros casos el tumor fue detectado por estudios realizados para investigar alteraciones no relacionadas con éste: enfermedad renal crónica, infecciones del tracto urinario, enfermedad prostática, hipertensión arterial o sintomas gastrointestinales. En 29 pacientes $(51,8 \%)$ se detectó hipertensión arterial. Siete pacientes $(12,5 \%)$ presentaron creatinina sérica $>1,4 \mathrm{mg} / \mathrm{dL}$. Por ecografia, en 23 casos $(41,1 \%)$ la masa fue localizada en el polo superior, en 15 $(26,8 \%)$ en el polo inferior, en $10(17,9 \%)$ en el área central del órgano, en $2(3,6 \%)$ ocupaba el riñón por completo y en los otros 6 casos no fue informada la localización.

Treinta y dos pacientes $(43,2 \%$ de 74$)$ presentaron tumores en estadio I de la UICC, $11(14,9 \%)$ tenian tumores en estadio II, $26(35,1 \%)$ tumores en estadio III y $5(6,8 \%)$ en estadio IV. Todos los oncocitomas estaban limitados al riñón.

\section{Características anatomopatológicas}

De acuerdo al tipo histológico, 22 casos $(29,7 \%)$ corresponden a CC; $37(50 \%)$ a CPC; 8 $(10,8 \%)$ a OC y $7(9,5 \%)$ a CDC. La masa fue macroscópicamente sólida en 46 casos $(62,2 \%)$, quística en $1(1,4 \%)$ y mixta en $21(28,4 \%)$, en los otros 6 casos esta característica no fue informada. La media del diámetro mayor fue de 7,5 $\pm 4,0$ cm. (mínimo - máximo: 2,5-23,0). En 6 de los 22 CC se encontró invasión de la vena renal principal, este hallazgo se detectó también en 2 CPC y en 1 CDC. No se encontró invasión venosa en ningún OC. El grado de Fuhrman fue significativamente más alto en los CDC (4 casos grado 3 y 3 grado 4$)$ que en los CC (10 casos grado 3 y 3 grado 4 ) y en CPC (5 casos grado 3 y 1 grado 4) $(\mathrm{P}<0,001)$. Solo $6 \mathrm{CC}$ y $1 \mathrm{CPC}$ presentaron transformación sarcomatosa. Las características citoplasmáticas de las células granulares en los cuatro tipos histológicos son relativamente similares, aunque los CDC mostraban más notorio pleomorfismo, desmoplasia y necrosis con respecto a los otros tres tipos de tumores.

\section{Histoquimica e Inmunohistoquimica}

La positividad con el método modificado de Mowry fue reticular, citoplasmática, fuerte y difusa en 32 de los 37 CPC y casi imperceptible en los otros 5 . El patrón difuso, fuerte y reticular no fue observado en ningún caso de $\mathrm{CC}, \mathrm{OC}$ o CDC. En 3 de los CC la tinción fue débil, citoplasmática, granular o como pequeñas gotas citoplasmáticas. La tinción en OC fue finamente granular, apical, débil y focal; fácilmente distinguible de la tinción de CPC.

Todos los casos fueron negativos para desmina, actina, HMB45, cromogranina, sinaptofisina, CD99 y CK10. La proteína S-100 fue débil y difusamente positiva en uno de los casos de CC (3+), todos los demás casos fueron negativos. CD34 fue positivo en 2 casos de CC, en uno de ellos 
débil y focal $(1+)$ y en el otro fuerte y difuso (3+). La CK20 fue positiva solo en un CDC, fuerte pero focal (1+). Los resultados con los demás anticuerpos se muestran en la Tabla 3.

El indice proliferativo (Ki67) fue $2,4 \% \pm 5,6 \%$ en $\mathrm{CC} ; 0,2 \% \pm 0,5 \%$ en CPC; $0,5 \% \pm 0,9 \%$ en OC, y $9,7 \% \pm$ $14,2 \%$ en $\mathrm{CDC}(\mathrm{P}=0,003)$.

El panel diagnóstico más útil fue CK7/CD10/ vimentina (Tablas 3 y 4). Las pruebas de rendimiento diagnóstico utilizando estos tres marcadores aparecen en la Tabla 4. Si adicionalmente a CK7/CD10/vimenti- Ulex na utilizamos el hierro coloidal con el método de Mowry modificado la especificidad y valor predictivo positivo son del $100 \%$.

Finalmente, en el seguimiento, 7 de los 18 CC, 1 de los 27 CPC, y 5 de los $7 \mathrm{CDC}$, en los que disponemos de esta información, presentaron metástasis $(\mathrm{P}<0,001)$. No había metástasis en ninguno de los $4 \mathrm{OC}$ con seguimiento clínico. 4 CDC y 1 CC presentaron recurrencia local. El promedio de seguimiento de los 56 casos con esta información fue $37,3 \pm$ 31,4 meses (mediana 32; mínimo máximo: 2-127)

\section{DISCUSIÓN}

El objetivo de nuestro trabajo CK 18 estuvo centrado en la búsqueda de diferencias en inmunofenotipo entre los tumores epiteliales renales con células granulares, como un método de ayuda en su diagnóstico diferencial. Encontramos diferencias considerables en la expresión de CK7, CD10 y vimentina entre los CC, CPC y OC. Si adicionalmente usamos el hierro coloidal (con el método modificado de Mowry) es posible el diagnóstico correcto en la mayoría de estos tumores con células granulares. Mientras que la mayoría de $\mathrm{CC}$ fueron CK7-/CD10+/vimentina+, los
Tabla 3. Características inmunohistoquímicas

\begin{tabular}{|c|c|c|c|c|}
\hline Anticuerpo $^{1}$ & $\mathbf{C C}$ & CPC & OC & CDC \\
\hline \multirow[t]{4}{*}{ EMA } & 0: 3 (13,6\%) & $0: 1(2,7 \%)$ & 0: $1(12,5 \%)$ & 0: $3(42,9 \%)$ \\
\hline & $1+: 5(22,7 \%)$ & $1+: 0$ & $1+: 0$ & $1+: 0$ \\
\hline & $2+: 4(18,2 \%)$ & $2+: 0$ & $2+: 0$ & $2+: 0$ \\
\hline & $3+: 10(45,5 \%)$ & $3+: 36(97,3 \%)$ & $3+: 7(87,5 \%)$ & $3+: 4(57,1 \%)$ \\
\hline \multirow[t]{4}{*}{ CEA } & 0: $7(31,8 \%)$ & 0: $13(35,1 \%)$ & 0: 6 (75\%) & 0: $2(28,6 \%)$ \\
\hline & $1+: 5(22,7 \%)$ & $1+: 13(35,1 \%)$ & $1+: 2(25 \%)$ & $1+: 1(14,3 \%)$ \\
\hline & $2+: 522,7 \%)$ & $2+: 8(21,6 \%)$ & $2+: 0$ & $2+: 1(14,3 \%)$ \\
\hline & $3+: 5(22,7 \%)$ & $3+: 3(8,1 \%)$ & $3+: 0$ & $3+: 3(42,9 \%)$ \\
\hline \multirow[t]{4}{*}{ Vimentina } & 0: 6 (27,3\%) & 0: $36(97,3 \%)$ & 0: $8(100 \%)$ & 0: $1(14,3 \%)$ \\
\hline & $1+: 4(18,2 \%)$ & $1+: 1(2,7 \%)$ & $1+: 0$ & $1+: 0$ \\
\hline & $2+: 4(18,2 \%)$ & $2+: 0$ & $2+: 0$ & $2+: 1(14,3 \%)$ \\
\hline & $3+: 8(36,4 \%)$ & $3+: 0$ & $3+: 0$ & $3+: 5(71,4 \%)$ \\
\hline \multirow[t]{4}{*}{ Ulex } & 0: 0 & 0: 2 (5,4\%) & $0: 0$ & 0: 0 \\
\hline & $1+: 5(22,7 \%)$ & $1+: 12(32,4 \%)$ & $1+: 0$ & $1+: 2(28,6 \%)$ \\
\hline & $2+: 11(50 \%)$ & $2+: 16(43,2 \%)$ & $2+: 2(25 \%)$ & $2+: 4(57,1 \%)$ \\
\hline & $3+: 6(27,3 \%)$ & $3+: 7(18,9 \%)$ & $3+: 6(75 \%)$ & $3+: 1(14,3 \%)$ \\
\hline \multirow[t]{4}{*}{ CD 10} & 0: $6(27,3 \%)$ & 0: 27 (73\%) & 0: $8(100 \%)$ & $0: 4(57,1 \%)$ \\
\hline & $1+: 1(4,5 \%)$ & $1+: 2(5,4 \%)$ & $1+: 0$ & $1+: 0$ \\
\hline & $2+: 2(9,1 \%)$ & $2+: 3(8,1 \%)$ & $2+: 0$ & $2+: 1(14,3 \%)$ \\
\hline & $3+: 13(59,1 \%)$ & $3+: 5(13,5 \%)$ & $3+: 0$ & $3+: 2(28,6 \%)$ \\
\hline \multirow[t]{4}{*}{ CD 15} & 0: $17(77,3 \%)$ & 0: $35(94,6 \%)$ & 0: $5(62,5 \%)$ & $0: 4(57,1 \%)$ \\
\hline & $1+: 1(4,5 \%)$ & $1+: 1(2,7 \%)$ & $1+: 0$ & $1+: 1(14,3 \%)$ \\
\hline & $2+: 1(4,5 \%)$ & $2+: 0$ & $2+: 1(12,5 \%)$ & $2+: 1(14,3 \%)$ \\
\hline & $3+: 3(13,6 \%)$ & $3+: 1(2,7 \%)$ & $3+: 2$ (25\%) & $3+: 1(14,3 \%)$ \\
\hline \multirow[t]{4}{*}{ CK 7} & 0: $20(90,9 \%)$ & $0: 3(8,1 \%)$ & 0: 8 (100\%) & 0: $3(42,9 \%)$ \\
\hline & $1+: 0$ & $1+: 1(2,7 \%)$ & $1+: 0$ & $1+: 0$ \\
\hline & $2+: 1(4,5 \%)$ & $2+: 12(32,4 \%)$ & $2+: 0$ & $2+: 3(42,9 \%)$ \\
\hline & $3+: 1(4,5 \%)$ & $3+: 21(56,8 \%)$ & $3+: 0$ & $3+: 1(14,3 \%)$ \\
\hline \multirow[t]{4}{*}{ CK 8} & 0: $17(77,3 \%)$ & $1+: 7(18,9 \%)$ & 0: 0 & 0: $2(28,6 \%)$ \\
\hline & $1+: 1(4,5 \%)$ & $2+: 7(18,9 \%)$ & $1+: 0$ & $1+: 1(14,3 \%)$ \\
\hline & $2+: 2(9,1 \%)$ & $3+: 16(43,2 \%)$ & $2+: 3(37,5 \%)$ & $2+: 3(42,9 \%)$ \\
\hline & $3+: 2(9,1 \%)$ & 0: $7(18,9 \%)$ & $3+: 5(62,5 \%)$ & $3+: 1(14,3 \%)$ \\
\hline \multirow[t]{4}{*}{ CK 18} & $0: 10(45,5 \%)$ & 0: $1(2,7 \%)$ & 0: 0 & $0: 3(42,9 \%)$ \\
\hline & $1+: 2(9,1 \%)$ & $1+: 0$ & 1+: 0 & $1+: 1(14,3 \%)$ \\
\hline & $2+: 6(27,3 \%)$ & $2+: 7(18,9 \%)$ & $2+: 2(25 \%)$ & $2+: 1(14,3 \%)$ \\
\hline & $3+: 4(18,2 \%)$ & $3+: 29(78,4 \%)$ & $3+: 6(75 \%)$ & $3+: 2(28,6)$ \\
\hline \multirow[t]{4}{*}{ CK 19} & 0: $17(77,3 \%)$ & 0: $30(81,1 \%)$ & 0: 6 (75\%) & 0: $2(28,6 \%)$ \\
\hline & $1+: 0$ & $1+: 3(8,1 \%)$ & $1+: 2(25 \%)$ & $1+: 0$ \\
\hline & $2+: 3(13,6 \%)$ & $2+: 11(2,7 \%)$ & $2+: 0$ & $2+: 1(14,3 \%)$ \\
\hline & $3+: 2(9,1 \%)$ & $3+: 3(8,1 \%)$ & $3+: 0$ & $3+: 4(57,1 \%)$ \\
\hline \multirow[t]{4}{*}{ HWCK } & 0: 22 (100\%) & 0: $35(94,6 \%)$ & 0: $8(100 \%)$ & 0: $6(85,7 \%)$ \\
\hline & $1+: 0$ & $1+: 2(5,4 \%)$ & $1+: 0$ & $1+: 0$ \\
\hline & $2+: 0$ & $2+: 0$ & $2+: 0$ & $2+: 1(14,3 \%)$ \\
\hline & $3+: 0$ & $3+: 0$ & $3+: 0$ & $3+: 0$ \\
\hline
\end{tabular}

$\mathrm{CC}$ : carcinoma convencional; $\mathrm{CDC}$ : carcinoma de conductos colectores; $\mathrm{CK}$ : citoqueratina CPC: carcinoma cromófobo; HWCK: citoqueratina de alto peso molecular. OC: oncocitoma; 0: negativo o reactivo en $<5 \%$ de las células tumorales; $1+$ : reactivo en $>5 \%$ y $\leq 30 \%$ de las células tumorales; $2+$ : reactivo en $>30 \%$ y $\leq 50 \%$ de las células tumorales; $3+$ : reactivo en $>50 \%$ de las células tumorales.

${ }^{1}$ Los anticuerpos negativos en todos o la mayoría de los casos no aparecen en la tabla; ver texto. 
Tabla 4. Resultados con el panel de inmunohistoquímica: CK7/CD10/vimentina

\begin{tabular}{|c|c|c|c|c|}
\hline & C. convencional & C. cromófobo & Oncocitoma & C. conductos colectores \\
\hline \multirow[t]{2}{*}{ CK 7} & Positivo: 2 & Positivo: 34 & Positivo: 0 & Positivo: 4 \\
\hline & Negativo: 22 & Negativo: 3 & Negativo: 8 & Negativo: 3 \\
\hline \multirow[t]{2}{*}{ CD10 } & Positivo: 16 & Positivo: 10 & Positivo: 0 & Positivo: 3 \\
\hline & Negativo: 6 & Negativo: 27 & Negativo: 8 & Negativo: 4 \\
\hline \multirow[t]{2}{*}{ Vimentina } & Positivo: 16 & Positivo: 1 & Positivo: 0 & Positivo: 6 \\
\hline & Negativo: 6 & Negativo: 36 & Negativo: 8 & Negativo: 1 \\
\hline Sensibilidad & $45 \%$ & $73 \%$ & $100 \%$ & -1 \\
\hline Especificidad $^{2}$ & $100 \%$ & $97 \%$ & $91 \%$ & -1 \\
\hline $\mathrm{VPP}^{2}$ & $100 \%$ & $96 \%$ & $57 \%$ & -1 \\
\hline VPN & $81 \%$ & $78 \%$ & $100 \%$ & -1 \\
\hline
\end{tabular}

CK: citoqueratina; VPP: valor predictivo positivo; VPN: valor predictivo negativo.

${ }^{1} \mathrm{El}$ carcinoma de conductos colectores no mostró un perfil específico útil en su diagnóstico diferencial.

${ }^{2} \mathrm{Si}$ adicionalmente a los tres anticuerpos incluimos el resultado para hierro coloidal, la especificidad y VPP son del $100 \%$.

CPC fueron CK7+/CD10-/vimentina-, y los OC negativos para los tres marcadores. Si bien este panel no es la prueba perfecta para el diagnóstico específico, el hierro coloidal complementa los estudios auxiliares y permite un diagnóstico específico. Estos resultados son consistentes con algunos estudios previos $3,6,9,15$. Otros estudios han explorado la utilidad individual de cada uno de los tres marcadores en el diagnóstico diferencial, pero su utilidad es muy limitada ${ }^{6,7,8}$. El panel que nosotros proponemos contiene tanto marcadores positivos como negativos para CC, CPC y OC. Los anticuerpos para CD10 y vimentina son incluidos como marcadores positivos para CC, y CK7 como marcador positivo para CPC. $\mathrm{CK} 7$ es incluido como marcador negativo para CC y OC, finalmente, CD10 y vimentina son incluidos como marcadores negativos para CPC y OC.

Las características morfológicas son muy importantes en el diagnóstico diferencial de los tumores renales con células granulares ${ }^{1,2,15,16}$ (Fig. 1). La mayoría de las neoplasias epiteliales renales pueden ser diagnosticadas confiablemente, por patólogos experimentados, basados únicamente en la morfología. Sin embargo, existen muchas similitudes morfológicas entre las neoplasias que presentan un extenso componente granular. La tinción fuerte y difusa con el hierro coloidal de Hale apoya el diagnóstico de CPC, como fue primero informado por Thoenes et al ${ }^{17}$ en la primera descripción del tumor, pero el método de Mowry modificado proporciona una tinción reticular más fuerte y claramente evidenciable, como fue descrito por Tickoo et $\mathrm{al}^{9}$. Sin embargo, esta tinción podría verse también en $\mathrm{CC}$ y $\mathrm{OC}^{4,9}$ y los errores en la interpretación de la tinción siguen siendo motivo de debate. $\mathrm{Si}$ bien la CK7, el CD10 y la vimentina han sido documentados en la literatura y en el presente trabajo como marcadores útiles, se debe tener precaución porque varios $\mathrm{CPC}$ y $\mathrm{OC}$ han sido informados como positivos con vimentina ${ }^{4}$, $y$ muchos carcinomas cromófobos han sido positivos para $\mathrm{CD} 10^{7,10}$. Es muy importante, según nuestro trabajo y otros, evaluar la intensidad y extensión de la tinción, una tinción débil y/o focal (menor del 30\% de las células) para CD10 o CK7 no es el rasgo característico en CC o CPC respectivamente.

En resumen, el diagnóstico diferencial de los tumores renales con citoplasma granular o eosinofilico es un reto diagnóstico relativamente común. Las características morfológicas son importantes: buscar áreas de células claras, halos perinucleares y abundante citoplasma reticular pálido con condensación del citoplasma hacia la membrana celular. El hierro coloidal con el método modificado de Mowry permite la confirmación de CPC en la mayoría de los casos. Aun así, el diagnóstico diferencial entre CC, CPC y OC 
no es siempre directo o fácil. Un panel con CD10, CK7 y vimentina podría ser útil para incrementar la precisión diagnóstica. Sin embargo, aún no existe un inmunomarcador específico para el diagnóstico de los subtipos de tumores de células epiteliales renales.

\section{REFERENCIAS}

1. Eble JN, Sauter G, Epstein JI, Sesterhenn IA (editores). World Health Organization Classification of Tumours. Pathology and Genetics of Tumours of the Urinary System and Male Genital Organs. Lyon, IARC Press. 2004, p 10.

2. Störkel S, Eble JN, Adlakha K, Amin M, Blute ML, Bostwick DG, et al. Classification of renal cell carcinoma: Workgroup No. 1. Union Internationale Contre le Cancer (UICC) and the American Joint Committee on Cancer (AJCC). Cancer. 1997;80(5):987-989.

3. Avery AK, Beckstead J, Renshaw AA, Corless CL. Use of antibodies to RCC and CD10 in differential diagnosis of renal neoplasms. Am J Surg Pathol. 2000;24(2):203-210.

4. Cochand-Priollet B, Molinié V, Bougaran J, Bouvier R, Dauge-Geffroy MC, Deslignières S, et al. Renal chromophobe cell carcinoma and oncocytoma. A comparative morphologic, histochemical, and immunohistochemical study of 124 cases. Arch Pathol Lab Med. 1997;121(10):1081-1086.

5. Kim MK, Kim S. Immunohistochemical profile of common epithelial neoplasms arising in the kidney. Appl Immunohistochem Mol Morphol. 2002;10(4):332-338.

6. Leroy X, Moukassa D, Copin MC, Saint F, Mazeman E, Gosselin B. Utility of cytokeratin 7 for distinguishing chromophobe renal cell carcinoma from renal oncocytoma. Eur Urol. 2000;37(4):484-487.

7. Martignoni G, Pea M, Brunelli M, Chilosi M, Zamo A, Bertaso M, et al. CD10 is expressed in a subset of chromophobe renal cell carcinomas. Mod Pathol. 2004;17(12): 1455-1463.

8. Mathers ME, Pollock AM, Marsh C, O'Donnell M. Cytokeratin 7: a useful adjunct in the diagnosis of chromophobe renal cell carcinoma. Histopathology. 2002;40(6): 563-567.
9. Tickoo SK, Amin MB, Zarbo RJ. Colloidal iron staining in renal epithelial neoplasms, including chromophobe renal cell carcinoma: emphasis on technique and patterns of staining. Am J Surg Pathol. 1998;22(4):419-424

10. Liu L, Qian J, Singh H, Meiers I, Zhou X, Bostwick DG. Immunohistochemical analysis of chromophobe renal cell carcinoma, renal oncocytoma, and clear cell carcinoma: an optimal and practical panel for differential diagnosis. Arch Pathol Lab Med. 2007;131(8):1290-1297.

11. Amin MB, Crotty TB, Tickoo SK, Farrow GM. Renal oncocytoma: a reappraisal of morphologic features with clinicopathologic findings in 80 cases. Am J Surg Pathol. 1997;21 (1): $1-12$.

12. Arias LF, Hernandez S, Prats D, Sanchez-Fructoso A, Márques M, Alvarez T, et al. Epstein-Barr virus latency in kidney specimens from transplant recipients. Nephrol Dial Transplant. 2003;18(12):2638-2643.

13. Kononen J, Bubendorf N, Kallioniemi A, Barlund M, Schraml P, Leighton S, et al. Tissue microarrays for highthroughput molecular profiling of tumor specimens. Nature Med. 1998;4(7):844-847.

14. Lillie RD, Fullmer HM. Histopathologic Technic and Practical Histochemistry. New York, McGraw-Hill Book Co. 1976, pp 611-678.

15. Latham B, Dickersin GR, Oliva E. Subtypes of chromophobe cell renal carcinoma. An ultrastructural and histochemical study of 13 cases. Am J Surg Pathol. 1999;23(5): 530-535.

16. Soung Sullivan P, Rao J, Cheng L, Cote RJ. Classical pathology versus molecular pathology in renal cell carcinoma. Curr Urol Rep. 2007;8(1):5-11.

17. Thoenes W, Storkel S, Rumpelt HJ. Human chromophobe cell renal carcinoma. Virchows Arch B Cell Pathol Incl Mol Pathol. 1985;48(3):207-217.

Correspondencia autor: Dr. LF Arias

Departamento de Patología, Facultad de Medicina

Universidad de Antioquia

Carrera 51D No. 62-29, Medellin, Colombia. Tel.: (+57) 42634455

E-mail: luisfer_uda@yahoo.com

Información artículo: Original - Cáncer renal

Trabajo recibido: julio 2007

Trabajo aceptado: noviembre 2007 